\title{
Sistem Monitoring Konversi Wifi-RSSI Menjadi Jarak Antar Device dan Router Menggunakan Node-Red Pada Pengembangan Sistem Navigasi Dalam Ruang
}

\section{A Monitoring System for Wifi-RSSI Conversion to Distance Between Device and Router Using Node-Red in Development of Narrow-Navigation System}

\author{
Rifqi Nafis Mubaroq ${ }^{1 *}$, Nina Siti Aminah ${ }^{2}$ \\ ${ }^{1,2}$ Kelompok Keilmuan Fisika Instrumentasi dan Komputasi, Fakultas Matematika dan \\ Ilmu Pengetahuan Alam, Institut Teknologi Bandung
}

\begin{tabular}{l} 
ARTICLE INFO \\
\hline Article history: \\
DOI: \\
10.30595/pspfs.v1i.130 \\
Submitted: \\
June 26, 2021 \\
Accepted: \\
July 10, 2021 \\
Published: \\
Oct 31, 2021 \\
\hline
\end{tabular}

Keywords:

Esp8266, Node-Red, Raspberry Pi, RSSI

\begin{abstract}
A global positioning system (GPS) is often used as a tool for determining direction and positioning. However, GPS is weak in estimating the error, which is quite large at the actual distance, so positioning in a narrow area cannot work well. Therefore, a better method is needed to be used as a narrow-navigation system. This study aimed to determine whether RSSI has a better error than GPS for navigation devices in a narrow space or area. The method used was plotting graphs using Ms. Excel and determining the value of $\mathrm{R}$ square. The RSSI value was obtained through the Esp8266 device and then sent to the server via the MQTT protocol and converted using Node-Red on the Raspberry Pi. The comparison results of the Esp8266 device RSSI graph match the Laptop RSSI device as a reference. The match between the relative distance to the RSSI with the actual distance shows a 3.3-33\% error. This result is considered much better than the GPS error.
\end{abstract}

This work is licensed under a Creative Commons Attribution 4.0 International License.

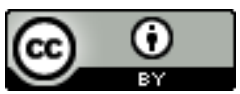

\section{Corresponding Author:}

Rifqi Nafis Mubaroq

Kelompok Keilmuan Fisika Instrumentasi dan Komputasi, Fakultas Matematika dan Ilmu Pengetahuan Alam, Institut Teknologi Bandung

J1. Ganesha No. 10 Bandung, 40132 Telp. 022-250 0935

Email: nina@fi.itb.ac.id

\section{PENDAHULUAN}

Dahulu penentuan arah seringkali menggunakan atlas, kompas, atau mata angin. Namun seiring berkembang dunia digital teknologi, penentuan arah sering menggunakan global positioning system (GPS). Meskipun demikian, GPS memiliki kelemahan yaitu estimasi galat yang cukup besar pada jarak sebenarnya sehingga penentuan posisi pada area yang cukup sempit tidak dapat berjalan dengan baik terutama di dalam ruang. Oleh karena itu, dibutuhkan metode yang lain yang lebih baik untuk digunakan sebagai sistem navigasi dalam ruang. salah satu alternatifnya adalah sistem navigasi menggunakan pemanfaatan nilai RSSI dari router.

Received Signal Strenght Indicator (RSSI) merupakan pengukuran daya yang ada dalam sinyal radio yang diterima (Parameswaran, 2009) atau teknologi yang digunakan untuk mengukur indikator kekuatan sinyal yang diterima oleh sebuah perangkat wireless. Nilai RSSI dapat dihasilkan dari perangkat-perangkat yang memiliki kemampuan menerima sinyal atau gelombang elektromagnetik. Salah satu perangkat penerima nilai RSSI yang cukup 
mudah ditemukan adalah Wemos D1 Mini (Esp8266) sedangkan Salah satu perangkat yang memiliki kemampuan mentransmisikan sinyal adalah WiFi (Wireless Fidelity).

Pada penelitian kali ini digunakan perangkat WiFi router karena perangkat tersebut sudah banyak terpasang dan digunakan di tempat-tempat umum. Sedangkan Wemos D1 Mini dipilih karena pembuatan program penerimaan nilai RSSI dan pengiriman data menuju server dirasakan lebih mudah dibandingkan dengan membuat aplikasi dari perangkat android. Router memiliki kemampuan mentransmisikan sinyal WiFi berupa gelombang elektromagnetik dan sinyal tersebut kemudian diterima oleh Wemos D1 Mini. Dari sinyal yang diterima kemudian diukur nilai RSSInya lalu nilai RSSI tersebut dijadikan sebagai acuan untuk menentukan posisi Wemos D1 Mini. metode ini dapat dijadikan solusi untuk navigasi dalam ruang.

Tujuan pada penelitian ini yaitu mengetahui apakah RSSI memiliki galat yang lebih baik dibandingkan GPS sebagai pemanfaatan perangkat navigasi dalam ruang atau area sempit dengan melakukan konversi sinyal RSSI menjadi Jarak antara Wemos D1 Mini dengan Router menggunakan Arduino IDE dan membuat sistem monitoring sinyal RSSI dan Positioning Perangkat berbasis Node-Red.

\section{METODE PENELITIAN}

Perencanaan skema alat yang akan digunakan untuk membuat alat sistem monitoring konversi nilai WiFi-RSSI menjadi jarak adalah sebagai berikut.

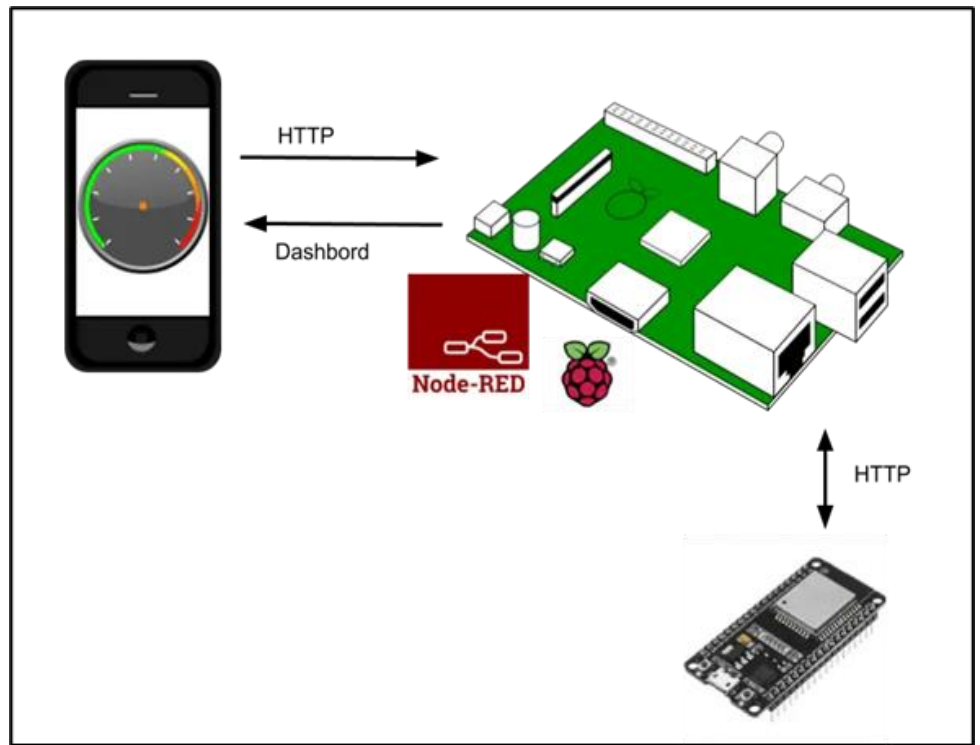

Gambar 1. Skema perencanaan alat

Sesuai dengan Gambar 1 di atas, sinyal RSSI akan dihasilkan dari perangkat Wemos D1 Mini atau Esp8266. Sinyal RSSI tersebut kemudian akan dikirimkan ke databes melalui MQTT Mosquitto menggunakan software Arduino IDE. Data pada MQTT kemudian diolah sehingga mendapatkan data jarak menggunakan metode plot grafik pada Ms. Excel menggunakan Node-Red pada Raspberry Pi 3B. Setelah mendapatkan data Jarak, maka data tersebut akan ditampilkan pada dashboard atau layar. Berdasarkan diagram blok di atas kemudian dibuatlah diagram alir untuk lebih memahami alur kerja alat monitoring konversi nilai WiFi-RSSI menjadi jarak, diagram alir dituliskan sebagai berikut: 


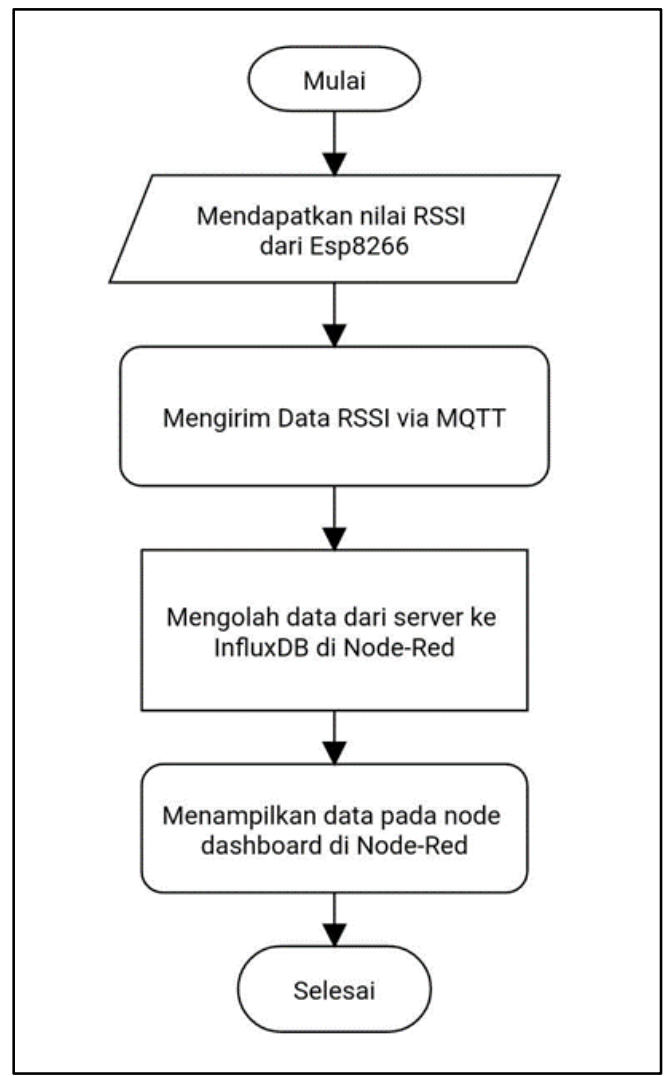

Gambar 2. Diagram alir alat monitoring konversi nilai WiFi-RSSI menjadi jarak

Nilai RSSI dari Esp8266 didapatkan dari hasil pembuatan algortima pada Arduino IDE sehingga nilai RSSI tersebut dapat ditampilkan dan dikirim menuju MQTT. Hasil tampilan RSSI pada Arduino IDE ditampilkan pada gambar berikut.

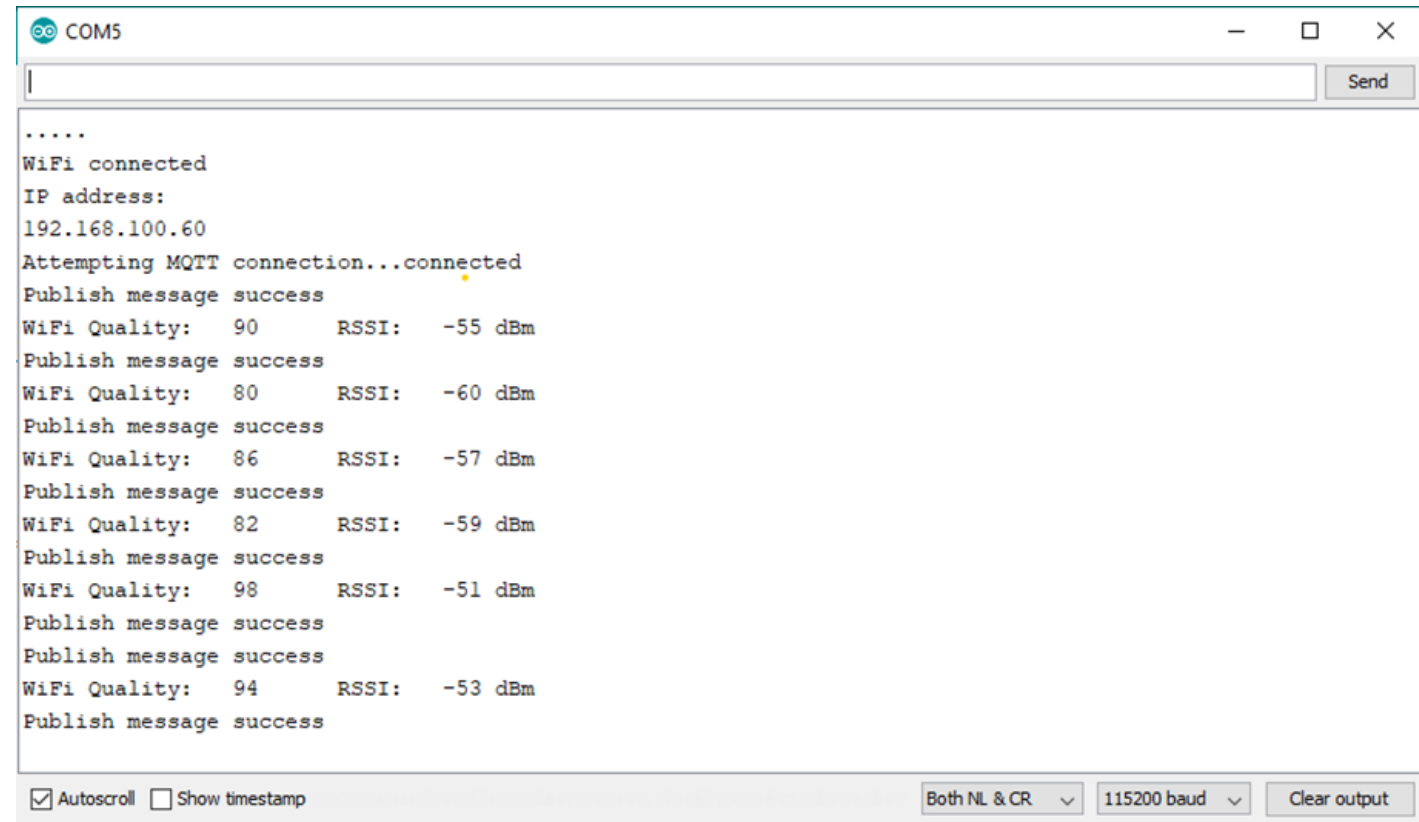

Gambar 3. Perolehan nilai RSSI dan pengiriman data ke MQTT 
Selanjuttnya Data dikirim menuju Node-Red dan dimasukkan ke Ms. Excel untuk menganalisis perbandingan nilai RSSI terhadap variasi jarak yang diukur secara manual sebagai acuan dalam sistem konversi yang akan dibangaun. Berikut tampilan Node hasil konfigurasi pembuatan sistem konersi RSSI ke jarak.

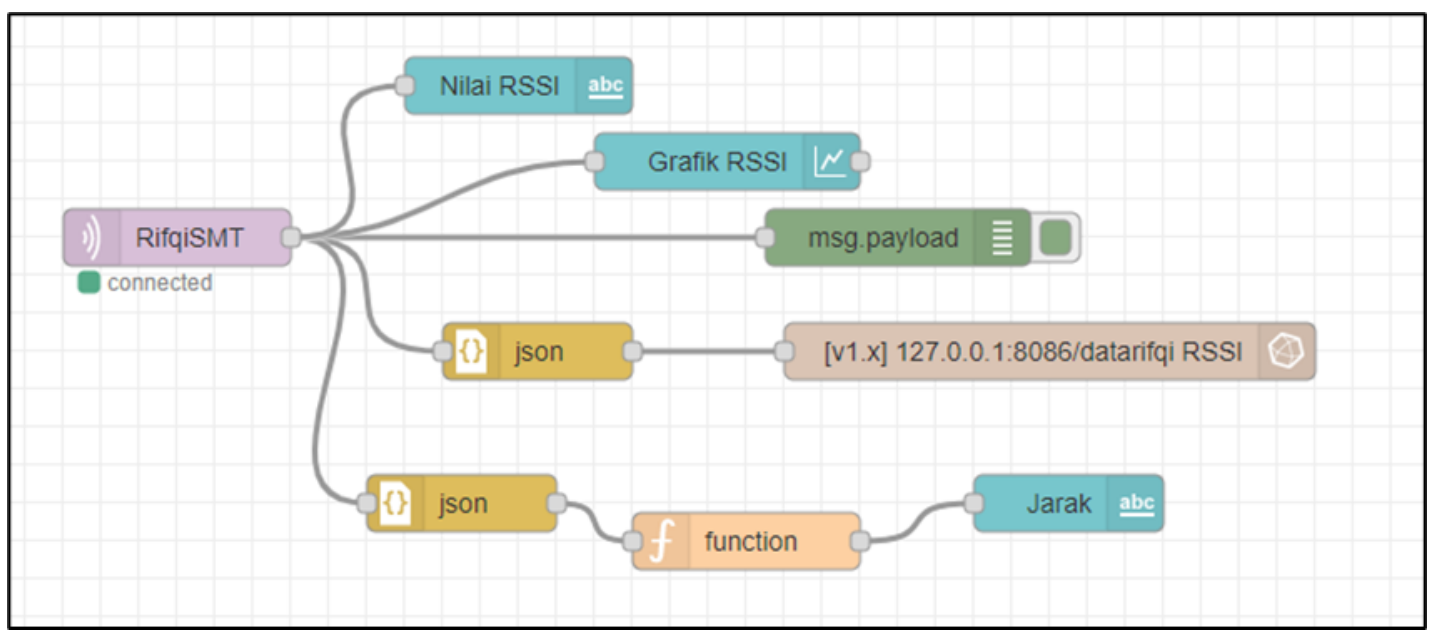

Gambar 4. Tampilan konfigurasi node pada Node-Red

Selanjutnya data yang di plot pada Ms. Excel akan menghasilkan suatu persamaan sesuai hasil interpolasi dan dijadikan acuan dalam mengubah atau mengkonversi nilai RSSI menjadi jarak. Selanjutnya data jarak akan ditampilkan pada layar atau dashboard sebagai perangkat monitoring. Berikut tampilan layar atau dashboard hasil pembuatan alat monitoring konversi nilai WiFi-RSSI menjadi jarak.

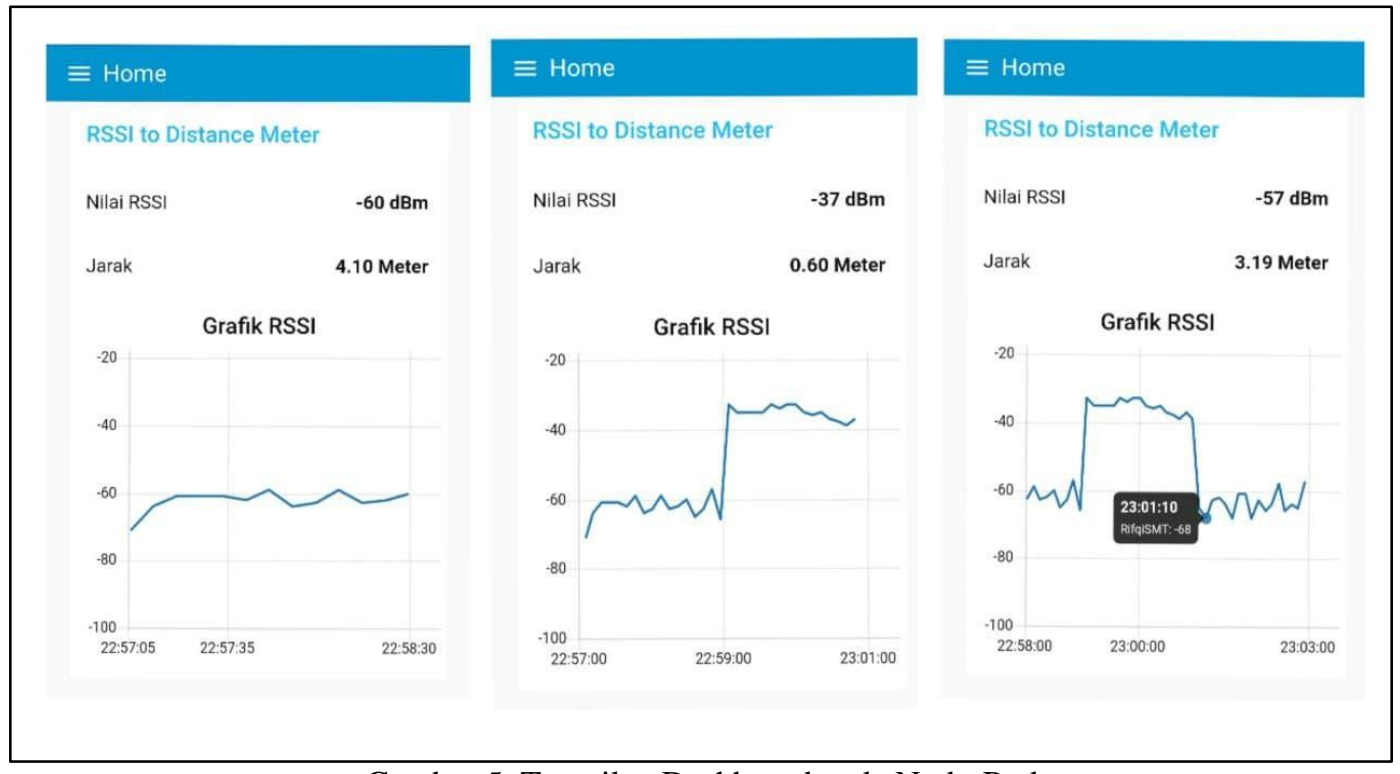

Gambar 5. Tampilan Dashboard pada Node-Red

\section{HASIL DAN PEMBAHASAN}

Berdasarkan eksperimen yang dilakukan, didapatkan data hasil nilai RSSI yang diperoleh menggunakan dua perangkat yaitu Esp9266 dan Laptop dengan menggunakan sofware Homedale. Hasil nilai RSSI kedua perangkat dibandingkan dengan melakukan variasi jarak. Data tersebut telah ditabulasikan pada Tabel 1 berikut. 
Tabel 1. Pengukuran nilai RSSI terhadap variasi jarak

\begin{tabular}{|c|c|c|c|c|}
\hline \multirow{2}{*}{ No } & \multirow{2}{*}{ Jarak (m) } & \multicolumn{2}{|c|}{ RSSI (dBm) } & \multirow{2}{*}{ Eror } \\
\hline & & Esp8266 & Homedale & \\
\hline 1 & 1 & -45 & -37 & 21.62 \\
\hline 2 & 3 & -55 & -53 & 3.77 \\
\hline 3 & 6 & -68 & -57 & 19.30 \\
\hline 4 & 9 & -69 & -60 & 15.00 \\
\hline 5 & 12 & -69 & -65 & 6.15 \\
\hline 6 & 15 & -73 & -70 & 4.29 \\
\hline 7 & 18 & -75 & -72 & 4.17 \\
\hline 8 & 21 & -80 & -78 & 2.56 \\
\hline 9 & 24 & -79 & -77 & 2.60 \\
\hline 10 & 27 & -82 & -80 & 2.50 \\
\hline 11 & 30 & -85 & -78 & 8.97 \\
\hline 12 & 33 & -86 & -82 & 4.88 \\
\hline 13 & 36 & -87 & -85 & 2.35 \\
\hline 14 & 39 & -89 & -85 & 4.71 \\
\hline 15 & 42 & -90 & -87 & 3.45 \\
\hline
\end{tabular}

Berdasarkan Tabel 1 diatas, Nilai RSSI yang didapatkan ole Esp8266 dibandingkan dengan nilai RSSI dari sofware Homadale. Didapatkan nilai eror yang bervariasi. Oleh karena 12 dari 15 data menghasilkan eror kurang dari $10 \%$ dan lebih dari setengah data memiliki eror kurang dari 5\%, maka perangkat Esp8266 dianggap cukup baik dan cocok dijadikan perangkat RSSI meter. Selanjutnya data RSSI yang diperoleh diplot dan dimodelkan menggunakan Ms. Excel agar dapat dibuat sistem konversi RSSI ke nilai jarak. Grafik Nilai RSSI terhadap variasi jarak ditunjukkan oleh grafik berikut.

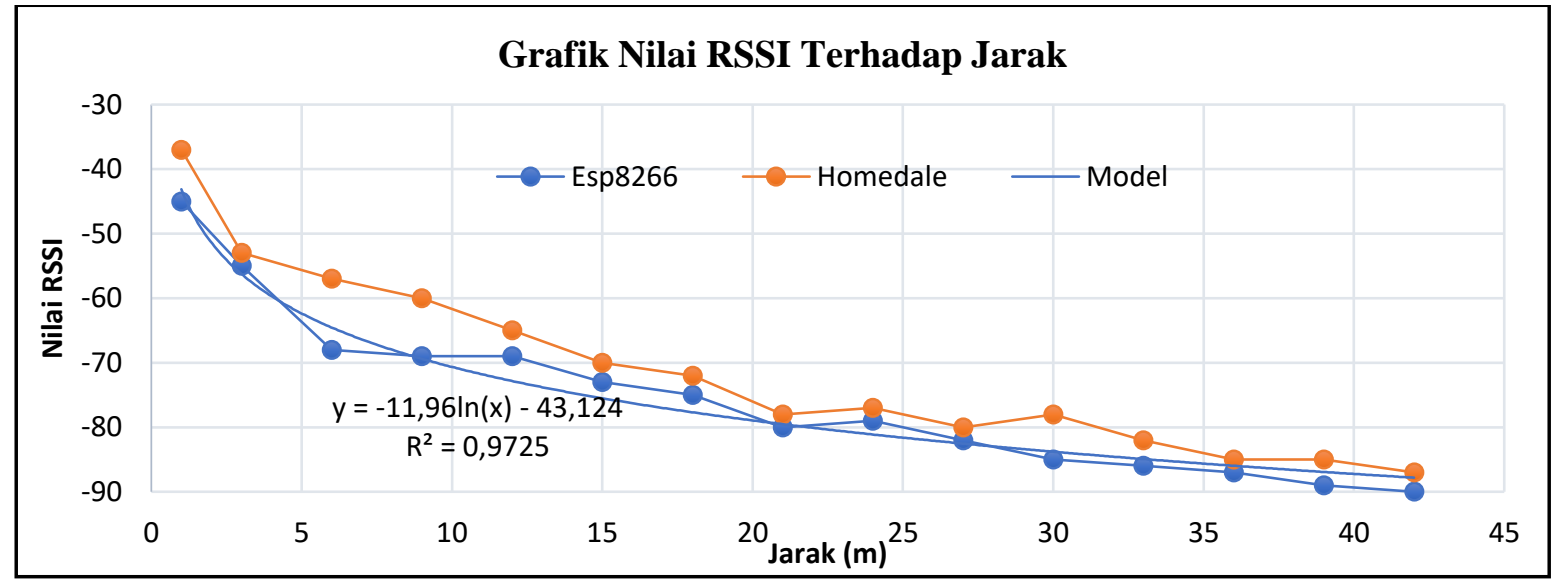

Gambar 6. Grafik pengukuran Nilai RSSI terhadap variasi jarak

Berdasarkan Gambar 7 diatas, Bisa dilihat trend nilai RSSI terhadap variasi jarak yang diberikan kedua perangkat baik Esp8266 maupun software Homedale menghasilkan pola yang sama, yakni semakin jauh perangkat terhadap router, maka nilai RSSI yang ditunjukkan semakin kecil atau kualitas signal yang dihasilkan semakin buruk. Pada grafik perangkat Esp8266 kemudian dilakukan pemodelan yang cocok menggunakan software Ms. Excel dan dihasilkan persamaan sebagai berikut dengan nilai R square sebesar 0,97 yang berarti memiliki tingkat keccokan yang tinggi.

$$
\operatorname{Jarak}=e^{-\frac{R S S I+43,124}{11,96}}
$$


Dengan jarak dalam meter, dan RSSI dalam dBm. Lalu persamaan tersebut dijadikan sebagai acuan dalam mengonversi nilai RSSI menjadi jarak antara Esp8266 dengan router. Setelah mendapatkan hasilnya, didapatkan estimasi pengukuran device menggunakan sistem konversi dan jarak sebenarnya yag telah ditabulasikan pada tabel 2 berikut.

Tabel 2. Perbandingan kecocokan nilai hasil RSSI meter

\begin{tabular}{cccc}
\hline $\begin{array}{c}\text { Nilai RSSI } \\
\text { Esp8266 (dBm) }\end{array}$ & $\begin{array}{c}\text { Jarak Sesuai } \\
\text { Model }(\mathbf{m})\end{array}$ & $\begin{array}{c}\text { Jarak } \\
\text { Sebenarnya }(\mathbf{m})\end{array}$ & Galat (\%) \\
\hline-45 & 1.16982736 & 1 & 16.98273658 \\
-55 & 2.699257104 & 3 & 10.02476319 \\
-68 & 8.003933516 & 6 & 33.39889194 \\
-69 & 8.701932701 & 9 & 3.31185888 \\
-69 & 8.701932701 & 12 & 27.48389416 \\
-73 & 12.158072 & 15 & 18.94618669 \\
-75 & 14.37107335 & 18 & 20.1607036 \\
-80 & 21.82983456 & 21 & 3.951593143 \\
-79 & 20.07882048 & 24 & 16.33824802 \\
-82 & 25.80328146 & 27 & 4.432290886 \\
-85 & 33.15978321 & 30 & 10.53261071 \\
-86 & 36.05154907 & 33 & 9.247118386 \\
-87 & 39.1954972 & 36 & 8.876381117 \\
-89 & 46.32982644 & 39 & 18.79442676 \\
-90 & 50.3701125 & 42 & 19.9288393 \\
\hline
\end{tabular}

Berdasarkan Tabel 2 diatas, Dapat dilihat bahwa eror hasil pengukuran jarak dengan hasil sebenarnya memiliki nilai yang bervariasi dari 3,3-33\%. Meskipun erornya cukup besar, namun hasil ini jauh lebih baik dibandingkan dengan galat dari GPS yang mencapai ribuan persen dalam skala meter. Hal ini menunjukkan bahwa RSSI dapat dijadikan sebagai salah satu alternatif dalam membangun sebuah sistem Navigasi.

\section{KESIMPULAN}

1. RSSI memiliki galat yang lebih baik dibandingkan GPS sebagai pemanfaatan perangkat navigasi dalam ruang atau area sempit.

2. Telah dilakukan konversi sinyal RSSI menjadi Jarak antara Wemos D1 Mini dengan Router menggunakan Arduino IDE dan Node-Red. Kode program dapat dilihat pada lampiran

3. Diperoleh rangkaian alat monitoring sinyal RSSI dan Positioning Perangkat berbasis Node-Red, rangkaian tersebut tersedia pada Gambar 6.

\section{UCAPAN TERIMA KASIH}

Penulis ingin menyampaikan terima kasih yang setulus-tulusnya kepada Kementerian Pendidikan dan Kebudayaan.

\section{DAFTAR PUSTAKA}

A. T. Parameswaran, M. I. Husain, and S. Upadhyaya. (2009) Is RSSI a reliable parameter in sensor localization algorithms - an experimental study. IEEE Int. Symp. Reliab. Distrib. Syst., pp. 1-5 